\title{
Biocontrol Potential of Metchnikowia pulcherrima Strains Against Blue Mold of Apple
}

\author{
W. J. Janisiewicz, T. J. Tworkoski, and C. P. Kurtzman
}

First and second authors: U.S. Department of Agriculture-Agricultural Research Service (USDA-ARS), Appalachian Fruit Research Station, Kearneysville, WV 25430; and third author: USDA-ARS, National Center for Agricultural Utilization Research, Peoria, IL 61604. Accepted for publication 26 July 2001.

\begin{abstract}
Janisiewicz, W. J., Tworkoski, T. J., and Kurtzman, C. P. 2001. Biocontrol potential of Metchnikowia pulcherrima strains against blue mold of apple. Phytopathology 91:1098-1108.

Eight strains of Metschnikowia pulcherrima isolated over a 4-year period from an unmanaged orchard and selected for their biocontrol activity against blue mold (caused by Penicillium expansum) of apples were characterized phenotypically, genetically, and for their biocontrol potential against blue mold on apples. All strains grew well and only differed slightly in their growth in nutrient yeast dextrose broth medium at $1{ }^{\circ} \mathrm{C}$ after $216 \mathrm{~h}$, but large differences occurred at $0^{\circ} \mathrm{C}$, with strain $\mathrm{T} 5$ A2 outgrowing other strains by more than $25 \%$ transmittance after $360 \mathrm{~h}$. This strain was also one of the most resistant to diphenylamine (DPA), a postharvest antioxidant treatment. All strains required biotin for growth in minimum salt (MS) medium, although strain ST2-A10 grew slightly in MS medium containing riboflavin or folic acid, as did ST3-E1 in MS medium without vitamins. None of the strains produced killer toxins against an indicator strain of Saccharomyces cerevisiae. Analysis of Biolog data from YT plates for all eight strains using the MLCLUST program resulted in separation of the strains into one major cluster containing four strains

and four scattered strains from which strain ST1-D10 was the most distant from all other strains. This was particularly apparent in 3-D and principle component analysis. Genetic differentiation of the eight strains using maximum parsimony analysis of nucleotide sequences from domain D1/D2 of nuclear large subunit (26S) ribosomal DNA resulted in detection of two clades. Strain ST1-D10 grouped with the type strain of M. pulcherrima but the remaining seven strains grouped separately, which might possibly represent a new species. All strains significantly reduced blue mold on mature Golden Delicious apples during 1 month of storage at $1{ }^{\circ} \mathrm{C}$ followed by 7 days at room temperature, but strains T5-A2 and T4-A 2 were distinctly more effective under these conditions. Strain T5-A2 also was the most effective in tests on harvest mature apples treated with the lowest concentration of the antagonist and stored for 3 months at $0.5^{\circ} \mathrm{C}$. Populations of all eight strains increased in apple wounds by approximately $2 \log$ units after 1 month at $1{ }^{\circ} \mathrm{C}$ followed by 5 days at $24^{\circ} \mathrm{C}$. Our results indicate that $M$. pulcherrima is an excellent candidate for biological control of postharvest diseases of pome fruit. The variation in phenotypic, genetic, and biocontrol characteristics among strains of $M$. pulcherrima isolated from the same orchard should make it possible to select antagonists with characteristics that are most desirable for postharvest application.
\end{abstract}

Biological control of postharvest diseases (BCPD) of fruits with antagonistic bacteria and yeasts has emerged as the most effective alternative to fungicides during the past few years. The initial products have been registered by the United States Environmental Protection Agency (EPA). BioSave 110 (EcoScience Corp., Orlando, FL), containing a saprophytic strain of Pseudomonas syringae van Hall, has been used commercially on pome fruit in the United States since 1996 (27,50). Although these pioneering products are effective, they have limitations with regard to spectrum of activity and efficacy under various environmental conditions and on various fruit. To address those limitations, new biocontrol approaches are being developed, such as applying mixtures of antagonists with superior biocontrol potential to individual antagonists $(24,25)$, combining antagonists with nonfungicidal methods such as heat treatment (8), cultural methods (44, $51)$, and substances that are generally regarded as safe $(8,14,26$, 58). Biological control also can be improved by more rigorous selection of the antagonists and physiological or genetic improvement of the antagonist strains to fulfill specific niche requirements and enhance biocontrol traits $(2,54,55)$

Since the first report on the occurrence of natural antagonists on fruit against blue mold, a postharvest fruit decay caused by

Corresponding author: W. J. Janisiewicz; E-mail address: wjanisie@afrs.ars.usda.gov

Publication no. P-2001-0911-01R

This article is in the public domain and not copyrightable. It may be freely reprinted with customary crediting of the source. The American Phytopathological Society, 2001.
Penicillium expansum Link (22), many effective bacterial (4,9, $12,28,36,48,49)$ and yeast $(6,7,15,17,20,29,31,32,34,37-41,43,46$, $51,56,57,59)$ antagonists were isolated from pome fruit worldwide. The most effective antagonists against decays of pome fruit were found among the resident microflora of apples. Of 13 yeast species reported to be residents of apple (10), 7 (6,7,15,20,29,34, $35,37,43,59)$ had strong antagonistic activity against postharvest decays of pome fruits.

The resident microflora of apple may vary from site to site and from season to season (10). Some species of yeasts have been isolated frequently from apples at various geographical locations, which confirms their resident status as described by Davenport (10). However, genetic and physiological niche requirements can vary among strains within a species, and intraspecies variation is poorly understood. Preliminary work with bacteria and yeasts isolated from an unmanaged orchard in Kearneysville, WV indicated significant differences in biocontrol potential among strains of the same species (W. J. Janisiewicz, unpublished data). It is likely that the biocontrol potential of strains of the same species from different locations may vary.

Strains of an antagonist species can be characterized for effectiveness in controlling fruit decay and for phenotypic characteristics that are useful in determining their commercial potential. For example, differentiation criteria for decay control on apple can include the biological control potential of the isolates (efficacy, spectrum of activity), ability to colonize the fruit surface under various conditions, utilization of substrates occurring in fruit, growth at cold storage temperatures and at $37^{\circ} \mathrm{C}$ (human body temperature), and compatibility with antioxidants (e.g., diphenyl- 
amine [DPA], used for control of superficial scald, a physiological disorder). Additional criteria may include resistance to environmental stress in the orchard, if biocontrol agents will be applied prior to harvest $(3,21,34,53,55)$, and pathogenicity of the antagonists to fruit, because strains of some antagonists with good biocontrol potential (e.g., Aureobasidum pullulans (de Bary) Arnaud) can cause minor decay on some fruit $(6,13,42)$.

Metschnikowia pulcherrima P. I. Pitt \& M. W. Miller has been recognized as one of the 13 resident species on cider apple trees (10). It has been frequently isolated from all floral parts and from buds of apple (10). It also has been one of the most frequently isolated microorganisms from wounded apple tissue in an orchard (24). It is also a dominant species on mature grapes (10) and on the bloom of icewine grapes (5). M. pulcherrima was reported to control Botrytis cinerea on apple $(39,41)$, and decays of peach and table grapes (11) after harvest. This yeast also has been frequently isolated in our work during the last decade and showed high levels of control of blue mold caused by $P$. expansum on pome fruits (W. J. Janisiewicz, unpublished data).

The objectives of this study were to determine biocontrol potential of various $M$. pulcherrima strains, isolated at different times from an unmanaged orchard, against blue mold of apple, and to determine variability among these strains based on characteristics important in postharvest biological control and genetic divergence used in the latest yeast taxonomy.

\section{MATERIALS AND METHODS}

Isolation of microorganisms. Microorganisms were isolated from wounds of artificially wounded 'Golden Delicious' or 'Red Delicious' (Malus domestica Borkh.) apples in a 6- to 10-year-old unmanaged apple orchard planted with Golden Delicious, Red Delicious, 'Empire', 'Stayman', and 'York' apple trees at the Appalachian Fruit Research Station in Kearneysville, WV, as described previously, with a few modifications (24). Briefly, Golden Delicious apples were wounded by removing the skin in an area of approximately $3 \mathrm{~cm}^{2}$ and $2 \mathrm{~mm}$ deep at weekly intervals starting 5 weeks before harvest in 1993; and only once, 4 weeks before harvest, in 1994. In 1997, Red Delicious apples were wounded 1 week before harvest. The wounded areas on fruit were removed for isolation of microorganisms with a cork borer $(1 \mathrm{~cm}$ in diameter by $1 \mathrm{~cm}$ deep) 1 week after each wounding in 1993; 1 , 2, 3, and 4 weeks after wounding in 1994; and 1 week after wounding in 1997. In 1993 and 1994, samples were ground with mortar and pestle in phosphate buffer and dilution plated on nutrient yeast dextrose agar (NYDA; Difco Laboratories, Detroit) medium and, after incubation, colonies were isolated and purified as described previously (24). In 1997, the samples were ground in $4.5 \mathrm{ml}$ of water and the resulting slurry was added to $200 \mathrm{ml}$ of $10 \%$ apple juice in 500-ml Erlenmeyer flasks, and shaken at $150 \mathrm{rpm}$ at $26^{\circ} \mathrm{C}$. At 42 and $66 \mathrm{~h}, 2 \mathrm{ml}$ of the culture was transferred to fresh $10 \%$ apple juice that was used for subsequent sampling. Samples for dilution plating were taken after 0, 24, 42, 66 , and $140 \mathrm{~h}$. After incubation of the plates, colonies were purified as described previously (24).

Pathogen and antagonists. The pathogen used was a very aggressive isolate of $P$. expansum (MD-8) from our collection that was previously isolated from a decayed apple in storage. It was maintained on potato dextrose agar (PDA; Difco Laboratories), and continued virulence was assured by periodic transfers through apple. A conidial suspension $\left(5 \times 10^{4}\right.$ conidia/ml $)$ was used for fruit inoculations as previously described (28).

The suspensions of the $M$. pulcherrima strains for fruit inoculation and nutrient utilization tests were prepared as described previously (28). Briefly, the yeasts were grown in $50 \mathrm{ml}$ of nutrient yeast dextrose broth (NYDB; Difco Laboratories) medium in 250-ml Erlenmeyer flasks on a rotary shaker at $150 \mathrm{rpm}$ at $26^{\circ} \mathrm{C}$. Following incubation for $24 \mathrm{~h}$, the cells were harvested by centrifugation at $7,000 \times g_{\mathrm{n}}$ for $10 \mathrm{~min}$, resuspended in water, and adjusted to a concentration $1.6 \times 10^{7} \mathrm{CFU} / \mathrm{ml}$ or $2.5 \times 10^{6} \mathrm{CFU} / \mathrm{ml}$ with a spectrophotometer at $420 \mathrm{~nm}$. For the biocontrol experiment described below, concentration adjustments were performed by 10 -fold dilutions of the original concentrations.

Antagonist selection and scale-up biocontrol tests. The biocontrol potential of the isolated microorganisms against $P$. expansum was determined in primary and secondary screening on Golden Delicious apples (23). Eight strains of $M$. pulcherrima (identified by Centraalbureau Voor Schimmelcultures, Delft, The Netherlands), which came from the three isolation procedures in 3 years and demonstrated strong biocontrol potential against blue mold in the screening tests, were selected for scale-up biocontrol tests on Golden Delicious apple, and a variety of other physiological and genetic tests. The selected yeast included strains T4-A2 and T5-A2 from the 1993 isolation; ST1-D10, ST2-A10, ST3-E1, and ST3-E13 from the 1994 isolation; and FMB-24H-2 and FMB$140 \mathrm{H}-7 \mathrm{~A}$ from the 1997 isolation. In the first test, very mature apples (firmness 45.4 Newtons) stored for 8 months at $1^{\circ} \mathrm{C}$ were removed from storage, washed, dried, placed on fruit tray packs, and equilibrated to room temperature over night. The next day, the fruit were wounded midway along the calyx-stem end axis with a standardized tool that had two six-penny nails ( $4 \mathrm{~mm}$ in diameter) placed $2 \mathrm{~cm}$ apart and protruding $3 \mathrm{~mm}$ from a wooden block.
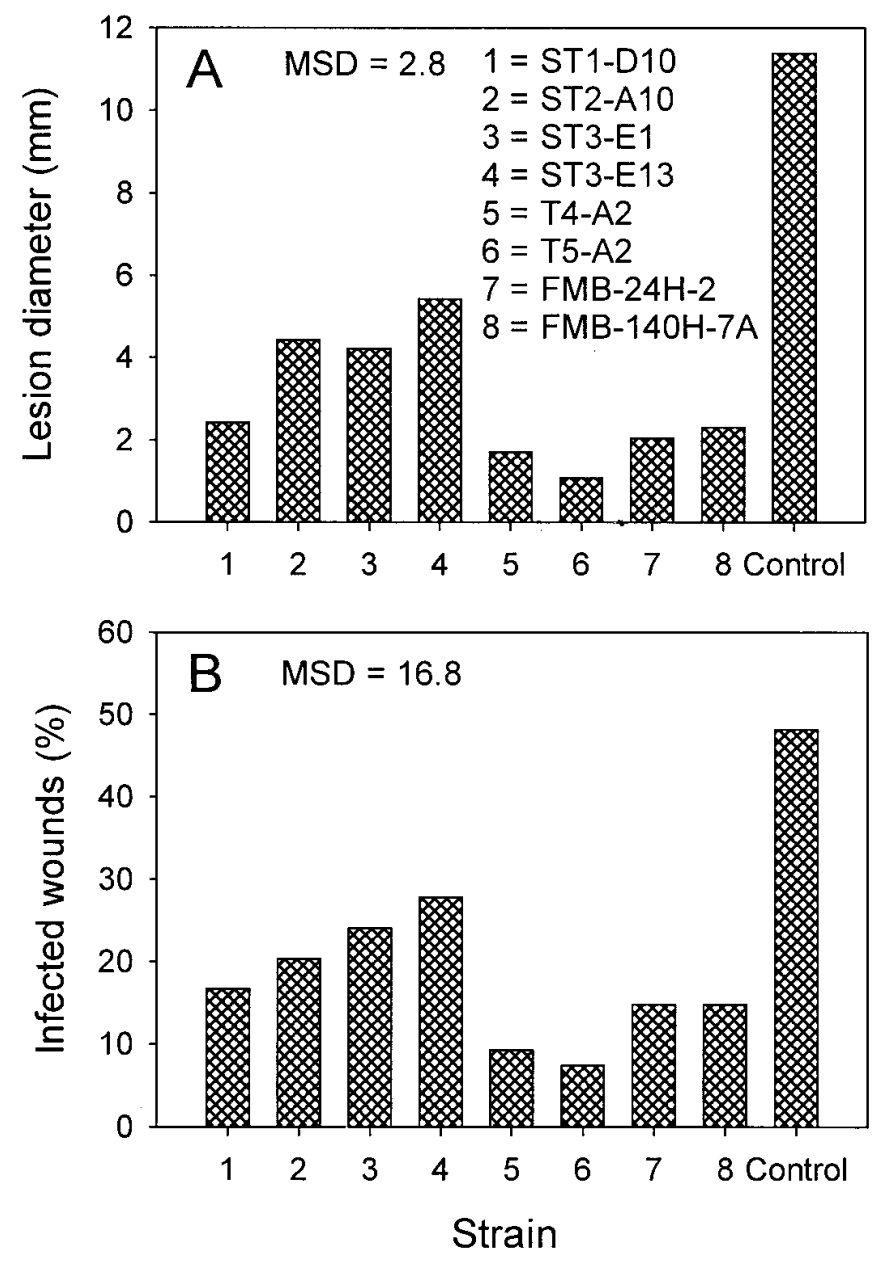

Fig. 1. Control of blue mold on mature (stored for 8 months at $1^{\circ} \mathrm{C}$ before application of treatments) 'Golden Delicious' apples, inoculated with Penicillium expansum alone (control) or in combination with the individual strains of Metchnikowia pulcherrima $\left(1.6 \times 10^{7} \mathrm{CFU} / \mathrm{ml}\right)$ and stored for 1 month at $1{ }^{\circ} \mathrm{C}$ followed by 7 days at room temperature. Minimum significant difference (MSD) is for comparing treatments with strains of $M$. pulcherrima; the control treatment was not included in the statistical analysis. 
Each wound was inoculated with $25 \mu \mathrm{l}$ of pathogen-antagonist mixture or the pathogen alone (control). The pathogen inoculum concentration was $5 \times 10^{4}$ conidia/ml and the antagonist was applied at $1.6 \times 10^{7} \mathrm{CFU} / \mathrm{ml}$. After inoculations, apples were placed in boxes with polyethylene liners and stored at $1{ }^{\circ} \mathrm{C}$ for 1 month. The fruit were then stored at room temperature for 7 days and evaluated for decay development. Measurement of decay severity on the fruit without decay was set to zero. There were three replicates per treatment and nine apples per replicate. The treatments were arranged in a completely randomized design. The results from this experiment confirmed our preliminary test, where only three apples were used per replicate.

In the second test, apples were used within 1 month after harvest. The fruit were inoculated as before and an additional two 1:10 dilutions of the original antagonist concentration were used. Approximately $1 \mathrm{~h}$ after inoculating the fruit, when the conidial suspension was no longer visible in the wounds, fruit were placed in wooden crates in polyethylene liners and stored at $0.5^{\circ} \mathrm{C}$ for 3 months. The treatments were arranged in completely randomized design. Additional experiment was conducted using the original antagonist concentration of $\approx 1 \times 10^{6} \mathrm{CFU} / \mathrm{ml}$.

The Waller-Duncan multiple-range test was performed for separation of means of lesion diameter and percentage of wounds infected on fruit treated with the eight strains of $M$. pulcherrima

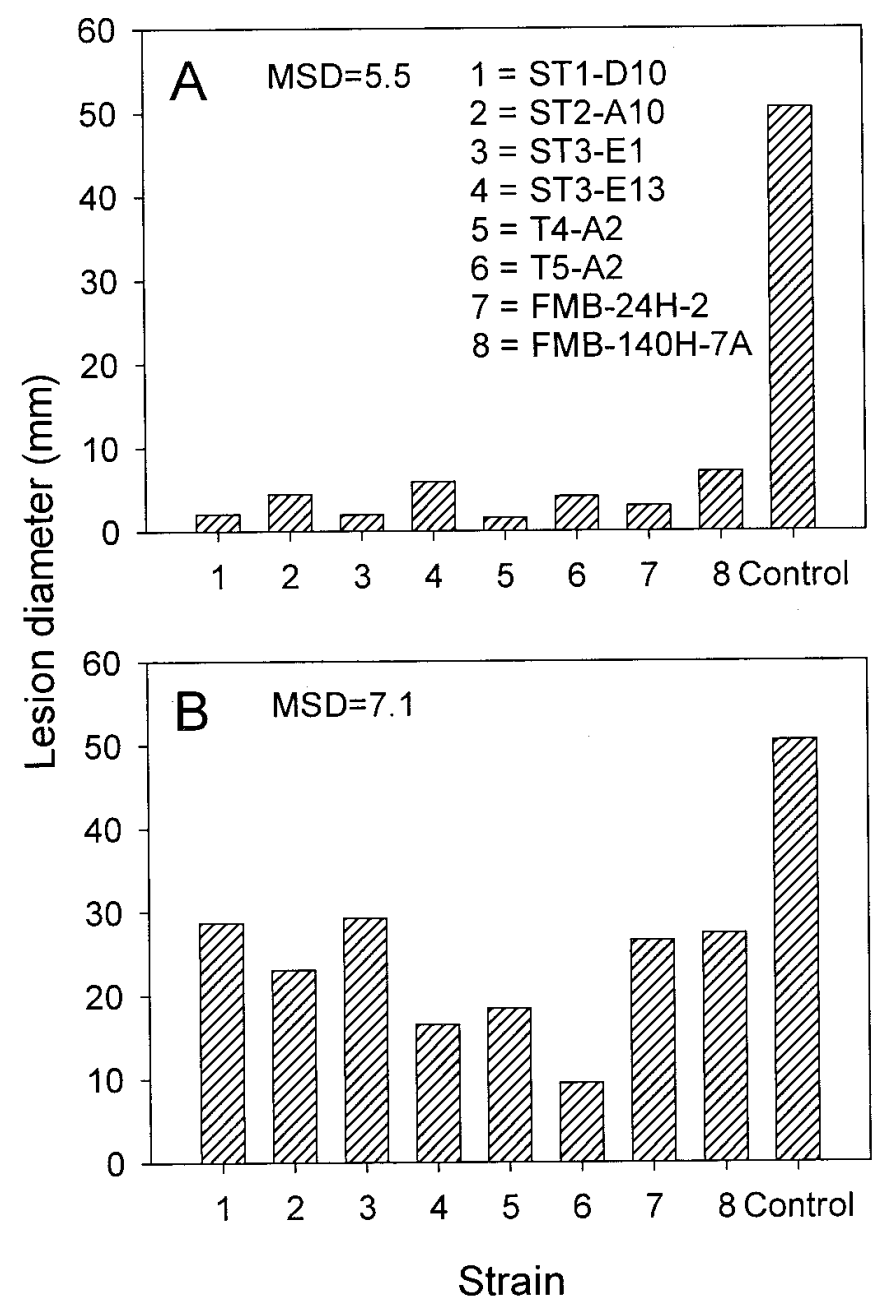

Fig. 2. Severity of blue mold decay on 'Golden Delicious' apples (stored for less than 1 month at $1^{\circ} \mathrm{C}$ before application of treatments) inoculated with Penicillium expansum alone (control) or in combination with the individual strains of Metchnikowia pulcherrima at A, $1.6 \times 10^{7} \mathrm{CFU} / \mathrm{ml}$ and B, $1.6 \times 10^{5} \mathrm{CFU} / \mathrm{ml}$ and stored for 3 months at $0.5^{\circ} \mathrm{C}$. Minimum significant difference (MSD) is for comparing treatments with strains of $M$. pulcherrima; the control treatment was not included in the statistical analysis. and $P$. expansum (SAS/STAT User's Guide, version 6, 4th ed.; SAS Institute Inc., Cary, NC).

Population dynamics on apple. Golden Delicious apples were wounded as above and inoculated with $25 \mu$ of $M$. pulcherrima strains at approximately $1.6 \times 10^{6} \mathrm{CFU} / \mathrm{ml}$. The yeast strains were isolated from the wounds within $2 \mathrm{~h}$ after application (time 0 ) and after 1 month in storage at $1^{\circ} \mathrm{C}$, followed by 5 days at $24^{\circ} \mathrm{C}$ according to the procedure described previously (27). Wounded tissue was removed with a cork borer, extracted with water in a Stomacher blender (Seward Medical, London, England), plated on NYDA medium with a Spiroplater (Spiral Biotech, Bethesda, $\mathrm{MD}$ ), and colonies were enumerated with a Casaba II laser counter and the Ben 4.0 program (Spiral Biotech) system. The experiment was repeated with the antagonist concentration of $\approx 2.5 \times$ $10^{6} \mathrm{CFU} / \mathrm{ml}$.

Growth at various temperatures. To determine growth of the strains at 0,1 , and $37^{\circ} \mathrm{C}$, the yeasts were grown in NYDB medium overnight and aqueous suspensions of the yeasts at $\approx 1.6 \times$ $10^{7} \mathrm{CFU} / \mathrm{ml}$ were prepared for each isolate as above. Then, 125-ml Erlenmeyer flasks, each containing $50 \mathrm{ml}$ of NYDB medium, were inoculated with $1 \mathrm{ml}$ of the yeast cell suspension and placed on a shaker at $150 \mathrm{rpm}$. Growth of the yeast in the flasks was determined by measuring the turbidity of the cultures at $640 \mathrm{~nm}$ at time intervals over 168, 216, and $360 \mathrm{~h}$ for flasks incubated at 37,1 , and $0^{\circ} \mathrm{C}$, respectively. Due to the lack of growth after $168 \mathrm{~h}$ at $37^{\circ} \mathrm{C}$, strain viability was determined by transferring

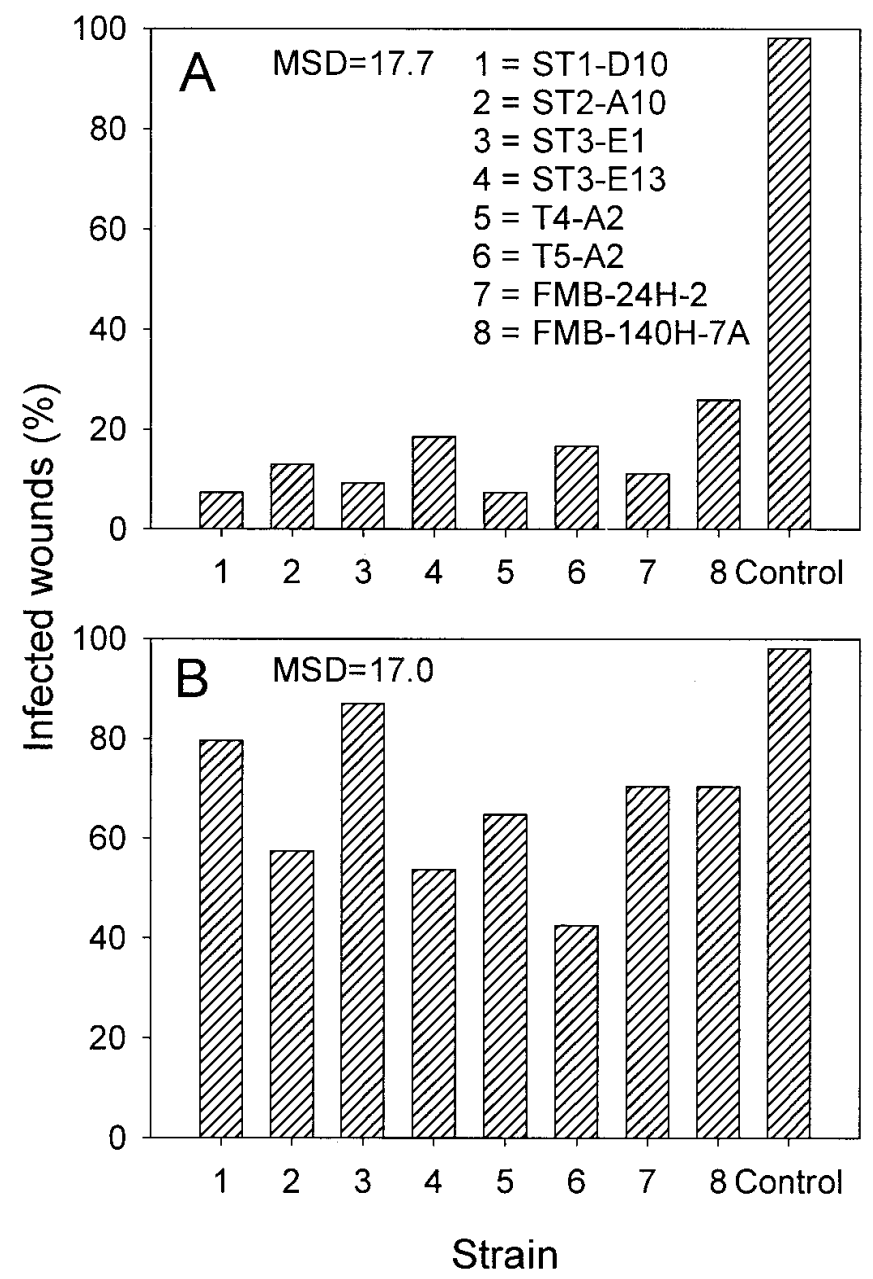

Fig. 3. Incidence of blue mold decay on 'Golden Delicious' apples inoculated with Penicillium expansum alone (control) or in combination with the individual strains of Metchnikowia pulcherrima at A, $1.6 \times 10^{7} \mathrm{CFU} / \mathrm{ml}$ and B, $1.6 \times 10^{5} \mathrm{CFU} / \mathrm{ml}$ and stored for 3 months at $0.5^{\circ} \mathrm{C}$. The control treatment was not included in the statistical analysis. 
the flasks to $26^{\circ} \mathrm{C}$ and determining the growth after an additional $72 \mathrm{~h}$. The identity of the strains in flasks with growth was confirmed by microscopic and visual observation of the colonies that grew after streaking the cultures on plates with NYDA medium and incubating them at $26^{\circ} \mathrm{C}$ for $72 \mathrm{~h}$. The experiment was repeated.

Tolerance to DPA. To determine the tolerance of the yeast strains to DPA, aqueous suspensions $(100 \mathrm{ml})$ of the yeasts were prepared in 250-ml Erlenmeyer flasks at a concentration of approximately $1.6 \times 10^{7} \mathrm{CFU} / \mathrm{ml}$ as described previously. Concentrated stock solutions $(1 \mathrm{ml})$ of two commercial DPA products, No Scald DPA EC-283 (Elf Atochem America, Inc. Monrovia, CA) or Shield DPA (Pace Int. LP, Kirkland, WA), were added to the yeast suspension to make a final concentration of $0.2 \%$ active ingredient (equal to the commercially recommended concentration of $2,000 \mathrm{ppm}$ ). The flasks were placed on a rotary shaker at $75 \mathrm{rpm}$ at $26^{\circ} \mathrm{C}$. The samples were collected at time intervals during 9 days, dilution-plated on NYDA medium with a Spiroplater, and colonies were counted with the Casaba II laser counter and BEN 4.0 program system after $48 \mathrm{~h}$ of incubation at $26^{\circ} \mathrm{C}$ as described above. There were three replications per treatment. The experiment was repeated.

Production of killer toxins. Killer yeasts secrete a toxin to which they are immune but which is lethal to sensitive yeasts. This phenomenon has been used in classification of yeast strains, including strains of $M$. pulcherrima. The eight $M$. pulcherrima strains were tested for production of the killer toxin using a sensitive strain of Saccharomyces cerevisiae NCYC 1006, (National Collection of Yeast Cultures, Norwich, U.K.) sensitive to the killer toxin (16). Filter-sterilized supernatants of the eight yeast cultures grown in NYDB for 7 days were evaluated by an agar diffusion test on NYDA plates. Wells, $1 \mathrm{~cm}$ in diameter, were made in the center of the agar plates using a cork borer and $100 \mu \mathrm{l}$ of the supernatant was placed in the wells. After $24 \mathrm{~h}$ of incubation at $4^{\circ} \mathrm{C}$, the plates were seeded with the 24-h-oldculture of the indicator strain and incubated at room temperature. The plates were evaluated daily for zones of growth inhibition. There were three plates per treatment. In the second test, the $M$. pulcherrima strains and the indicator strain of $S$. cerevisiae were streaked perpendicularly across the NYDA plates without touching each other. The streaks with the eight isolates were made $24 \mathrm{~h}$

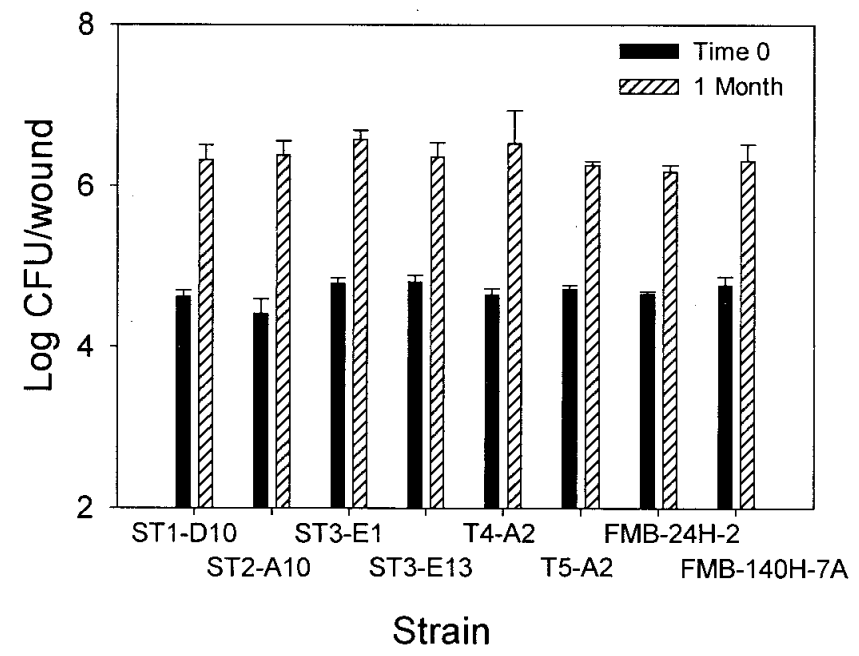

Fig. 4. Populations of Metchnikowia pulcherrima strains in wounds of 'Golden Delicious' apple at the time of inoculation (time 0) and after 1 month of storage at $1{ }^{\circ} \mathrm{C}$ followed by 5 days at $24^{\circ} \mathrm{C}$. To determine population sizes in the wounds, the wounded area was removed with a cork borer, extracted in water using a Stomacher blender, dilution-plated on nutrient yeast dextrose agar medium, and colonies were counted after incubation for $48 \mathrm{~h}$ at $26^{\circ} \mathrm{C}$. Bars indicate $\pm \mathrm{SD}$. before the streak with the indicator strain. The plates were evaluated daily for 5 days for growth inhibition of the indicator strain. There were three plates per treatment.

Vitamin requirements. The requirement of the yeast strains for vitamins was determined in minimum salt (MS) medium as described by Barnett et al. (1). Briefly, nine vitamins: ( $p$-aminobenzoic acid, $200 \mu \mathrm{g} / \mathrm{liter}$; biotin, $20 \mu \mathrm{g} / \mathrm{liter}$; folic acid, $2 \mu \mathrm{g} / \mathrm{liter}$; myo-inositol, $10 \mathrm{mg} / \mathrm{liter}$; nicotinic acid, $400 \mu \mathrm{g} / \mathrm{liter}$; pantothenate [Ca], $2 \mathrm{mg} /$ liter; pyridoxine $\mathrm{HCl}, 400 \mu \mathrm{g} /$ liter; riboflavin, 200 $\mu \mathrm{g} /$ liter; and thiamine $\mathrm{HCl}, 400 \mu \mathrm{g} / \mathrm{liter}$ ), individually or in combination, were added to $50 \mathrm{ml}$ of the MS medium in $125-\mathrm{ml}$ Erlenmeyer flasks. The flasks were inoculated with $1 \mathrm{ml}$ of $\approx 1.6 \times$
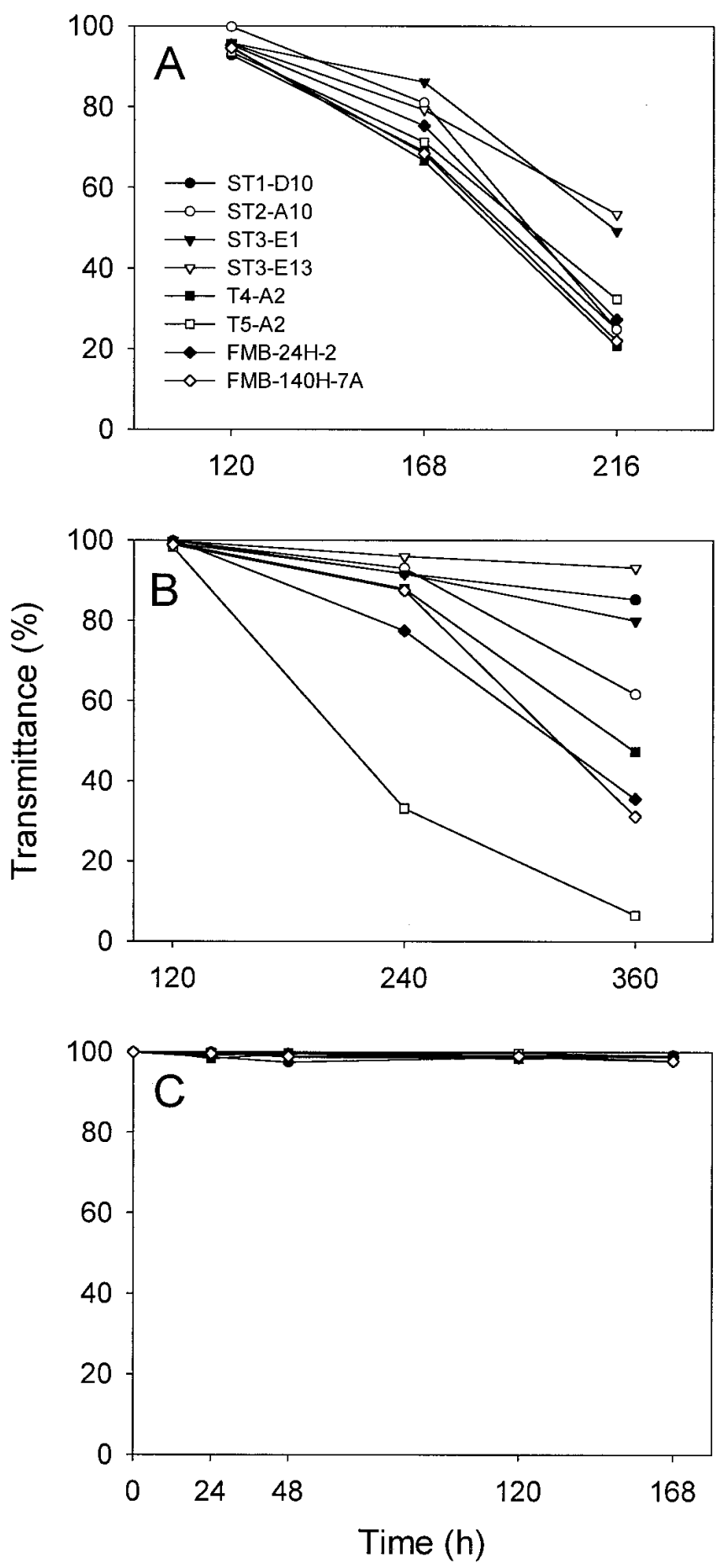

Fig. 5. Growth of the eight strains of Metchnikowia pulcherrima in nutrient yeast dextrose broth medium at $\mathbf{A}, 1^{\circ} \mathrm{C}, \mathbf{B}, 0^{\circ} \mathrm{C}$, and $\mathbf{C}, 37^{\circ} \mathrm{C}$. 
$10^{7} \mathrm{CFU} / \mathrm{ml}$ of aqueous suspensions of the $M$. pulcherrima strains and incubated on a shaker at $150 \mathrm{rpm}$ at $26^{\circ} \mathrm{C}$. Turbidity of the cultures at $420 \mathrm{~nm}$ was determined immediately after inoculation and after growth for $22 \mathrm{~h}( \pm 2 \mathrm{~h})$. The experiment was conducted twice with similar results, the first time on individual strains at various times and the second time on all strains concurrently.

Utilization of amino acids. To determine the ability of the yeast to utilize the major amino acids present in apple juices tissue
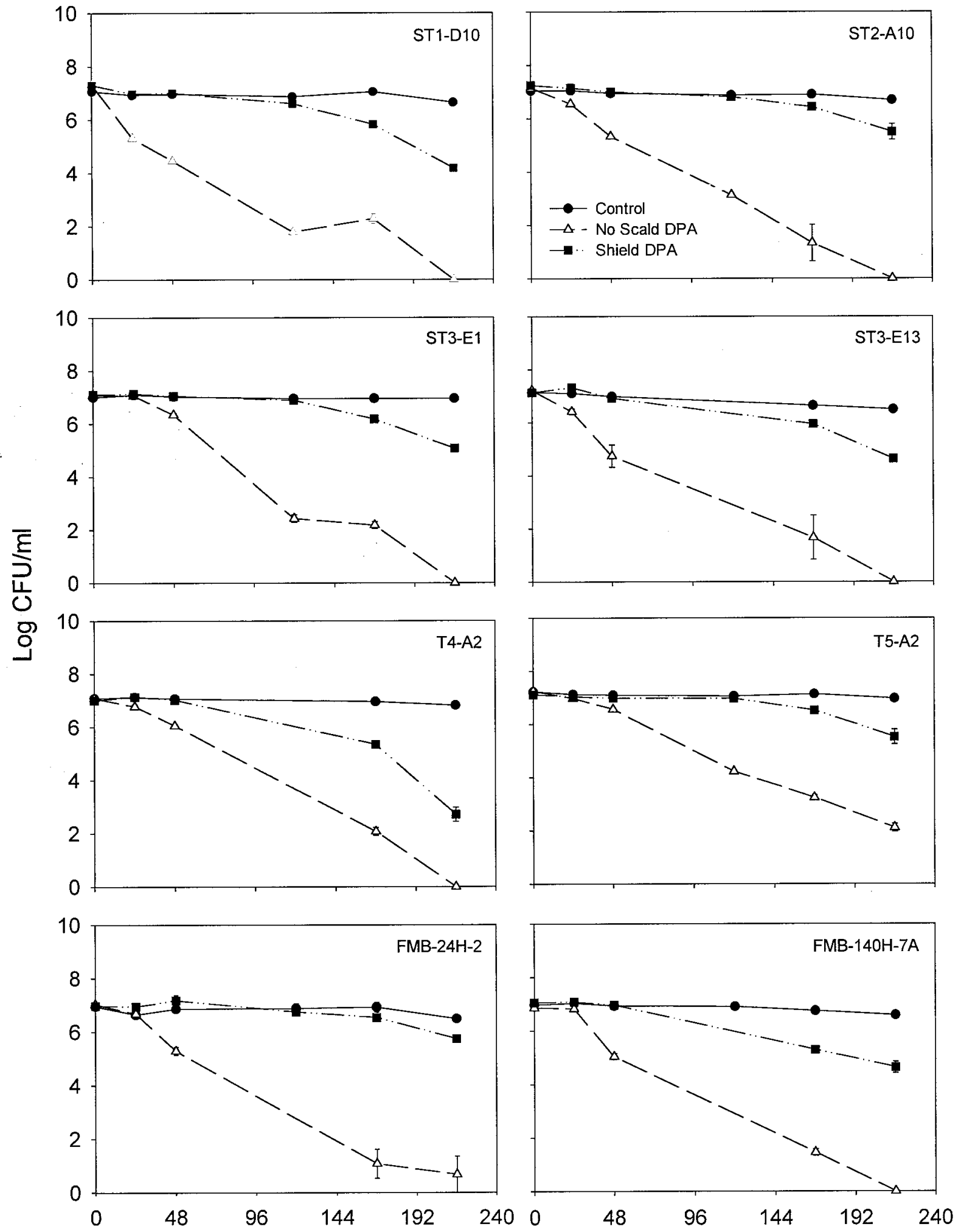

Time (h)

Fig. 6. Survival of the eight strains of Metchnikowia pulcherrima in water (control), or aqueous suspensions of two commercial products, No-Scald DPA or Shield DPA. Samples were taken from the flasks at intervals, dilution-plated on nutrient yeast dextrose agar medium, and colonies were counted after $48 \mathrm{~h}$ of incubation at $26^{\circ} \mathrm{C}$. The concentration of the active ingredient diphenylamine (DPA) in the suspensions was at the commercially recommended rate of $0.2 \%$ $(2,000 \mathrm{ppm})$. Bars indicate \pm SD. 
culture plastic plates (Costar, Corning Inc., Corning, NY) were used as described previously (30). Briefly, 5\% apple juice alone or with the yeast at a concentration $1.6 \times 10^{6} \mathrm{CFU} / \mathrm{ml}$ was dispensed into the wells of the plates $(1 \mathrm{ml}$ per well). Suspensions containing an antagonist in apple juice were prepared by mixing $1: 1$ ( $\mathrm{vol} / \mathrm{vol})$ of $10 \%$ apple juice and the water suspension of the antagonists. Then, $1 \mathrm{ml}$ of this suspension was placed in the wells and incubated at $26^{\circ} \mathrm{C}$. Samples for time 0 were collected within $5 \mathrm{~min}$ after mixing the antagonist with the juice. There were three replicates (three wells) for each isolate at each sampling time. Concentration of the three dominant amino acids (asparagine, glutamic acid, and aspartic acid) was determined with high pressure liquid chromatography using the procedure described earlier (30). The experiment was conducted twice with similar results. The time interval was 2 and $1.5 \mathrm{~h}$ and duration of the experiment was 6 and $4.5 \mathrm{~h}$ for the first and second experiment, respectively.

Biolog differentiation of $M$. pulcherrima strains. The growth potential on various carbon and nitrogen sources and the resulting relatedness of $M$. pulcherrima strains was determined with YT Biolog plates of the Biolog system (Biolog Inc., Hayward, CA) according to the recommended procedure. The plates were inoculated with the yeast suspensions made from cultures grown in NYDB medium overnight, which were washed twice in sterile distilled water before application to the plates. The data from the YT plates was analyzed with the MLCLUST program (Biolog Inc.). The experiment was conducted twice with similar results. In the first test, the YT plates were inoculated with different strains at different times and, in the second test, all strains were inoculated concurrently.

Genetic differentiation of $M$. pulcherrima strains. Genetic differentiation of $M$. pulcherrima strains was determined using analysis of divergence of the nucleotide sequence in the variable D1/D2 domain ( $\approx 600$ nucleotides) of large subunit (26S) ribosomal DNA according to the procedure described by Kurtzman and Robnett (33). Sequences of the eight putative $M$. pulcherrima strains were initially compared against a database of D1/D2 sequences from all known ascomycetous yeasts using the maximum parsimony program of PAUP 4.063a (52). The nearest neighbors in this analysis were $M$. pulcherrima (NRRL Y-7111, type strain) and $M$. reukaufii (NRRL Y-7112, type strain). A recompiled dataset comprised of the eight strains along with $M$. pulcherrima and $M$. reukaufii (outgroup species in the analysis) was again analyzed by maximum parsimony with heurisitic searches employing both simple and random sequence additions. Confidence limits for phylogenetic trees were estimated from bootstrap analysis $(1,000$ replications).

\section{RESULTS}

Biocontrol potential. In the first test, on mature apples stored for 8 months before application of the treatment, all strains re- duced severity and incidence of decay. Apples treated with strain T5-A2 had the smallest lesion, and those protected with this strain and T4-A2 had the lowest incidence of decay (Fig. 1A and B).

In the second test, little decay developed at the highest concentration of the antagonist, and there were no significant differences among antagonists except strain FMB-140H-7A, which had significantly higher severity and incidence of decay (Figs. 2 and 3). On fruit protected with antagonists diluted 100-fold, treatment with strain T5-A2 had the smallest lesion and the lowest incidence of decay (Figs. 2 and 3). The next treatments with the smallest lesions were strains ST3-E13, T4-A2, and ST2-A10, and with the lowest incidence of decay strains ST3-E13 and ST2-A10, followed by T4-A2.

Population dynamics on apple. All eight strains grew well in apple wounds over 1 month at $1^{\circ} \mathrm{C}$ followed by 5 days at $24^{\circ} \mathrm{C}$. During this period, populations increased approximately $2 \mathrm{log}$ units for all strains (Fig. 4).

Growth at various temperature. All strains grew in NYDB medium at $1{ }^{\circ} \mathrm{C}$ (Fig. 5). Two strains, ST3-E1 and ST3-E13, grew distinctively slower and, after $216 \mathrm{~h}$, their growth was at least $18 \%$ transmittance less than the other strains. At $0^{\circ} \mathrm{C}$, there was greater separation between strains, with strains ST3-E1, ST3-E13, and ST1-D10 growing the slowest and strain T5-A2 outgrowing all other strains by more than $25 \%$ transmittance after $360 \mathrm{~h}$. None of the eight strains grew in NYDB medium at $37^{\circ} \mathrm{C}$ (Fig. 5). After moving the flasks from 37 to $26^{\circ} \mathrm{C}$, five strains (ST2-A10, ST3E1, ST3-E13, T4-A2, and T5-A2) resumed growth and reached turbidity below $10 \%$ transmittance after an additional $72 \mathrm{~h}$ of incubation. No growth occurred in flasks with strains ST1-D10, FMB-24H-2, and FMB140H-7A (data not shown).

Tolerance to DPA. There were significant differences in the tolerance of the eight $M$. pulcherrima strains to two different formulations of DPA (Fig. 6). Populations of all strains declined greatly in No Scald DPA and were not recovered in six of the eight strains after 9 days. Strains T5-A2 and FMB-24H-2 were recovered after $216 \mathrm{~h}$, with strain T5-A2 having almost two logs greater populations than FMB-24H-2. Shield DPA had a much less negative effect on the survival of the yeasts. The populations started to decline noticeably after 5 days and generally did not decline more than two log units after 9 days. The only exception was strain T4-A2, which declined more than four log units by the end of the experiment.

Production of killer toxins. None of the eight $M$. pulcherrima strains produced killer toxins, and none inhibited the growth of the indicator strain of S. cerevisiae (NCYC 1006) in the culture filtrate agar diffusion test or the cross-streak test on NYDA plates.

Vitamin requirements. All strains required Biotin for normal growth (Table 1). Strain ST2-A10 had limited growth on folic acid and riboflavin, and strain ST3-E1 had very limited growth in media without vitamins. Growth with a mixture of vitamins was

TABLE 1. Growth of Metchnikowia pulcherrima strains in minimum salt (MS) medium containing individual vitamins and their mixture

\begin{tabular}{|c|c|c|c|c|c|c|c|c|}
\hline \multirow[b]{2}{*}{ Vitamin } & \multicolumn{8}{|c|}{ Strain $(\% \text { transmittance, } 420 \mathrm{~nm} \text {, after } 22 \mathrm{~h})^{\mathrm{a}}$} \\
\hline & ST1-D10 & ST2-A10 & ST3-E1 & ST3-E13 & T4-A2 & T5-A2 & FMB-24H-2 & FMB-140H-7A \\
\hline p-Aminobenzoic acid & 99.7 & 99.2 & 93.2 & 96.9 & 99.9 & 99.0 & 98.3 & 99.6 \\
\hline Biotin & 18.6 & 10.2 & 7.9 & 10.8 & 11.8 & 8.7 & 11.2 & 13.0 \\
\hline Folic acid & 99.7 & 89.6 & 93.6 & 98.7 & 99.9 & 99.9 & 99.0 & 99.7 \\
\hline Myo-inositol & 99.8 & 93.5 & 95.2 & 97.8 & 99.6 & 99.6 & 99.1 & 99.5 \\
\hline Nicotinic acid & 99.2 & 98.3 & 95.2 & 98.8 & 99.9 & 99.5 & 99.1 & 99.8 \\
\hline d-Pantothenate & 99.5 & 98.8 & 95.0 & 98.4 & 99.9 & 99.3 & 98.6 & 99.5 \\
\hline Pyridoxine $\mathrm{HCl}$ & 99.4 & 96.4 & 94.9 & 96.8 & 99.9 & 98.2 & 98.9 & 99.0 \\
\hline Riboflavin & 99.7 & 78.5 & 94.2 & 98.8 & 99.8 & 99.5 & 99.2 & 99.3 \\
\hline Thiamin $\mathrm{HCl}$ & 99.8 & 93.8 & 93.7 & 98.5 & 99.7 & 98.4 & 97.8 & 99.8 \\
\hline Mixture & 9.5 & 8.7 & 8.2 & 8.8 & 10.6 & 9.7 & 11.0 & 12.3 \\
\hline None & 99.6 & ND & 94.1 & 97.5 & 99.8 & 98.6 & 98.2 & 99.5 \\
\hline
\end{tabular}

a Time $\pm 2 \mathrm{~h}$; addition of vitamin mixture and yeasts to MS medium reduced transmittance by $<1 \%$ for all samples at $0 \mathrm{~h}$. 
generally similar to growth with biotin alone except with strain ST1-D10, where percent transmittance in the mixture was almost half of that with the biotin.

Utilization of amino acids. The three main amino acids in apple juice (asparagine, aspartic acid, and glutamic acid) were utilized by all strains. Asparagine, aspartic acid, and glutamic acid concentrations of juice at time 0 were $0.161,0.042$, and $0.028 \mathrm{mM}$, respectively. Amino acid concentrations at time 0 (immediately after mixing juice with the antagonists) was not modified by strain T5-A2 but was reduced by all other strains (Fig. 7). Amino acids were completely depleted by all strains except ST3-E1 and FMB$24 \mathrm{H}-2$ within $4.5 \mathrm{~h}$ of mixing.

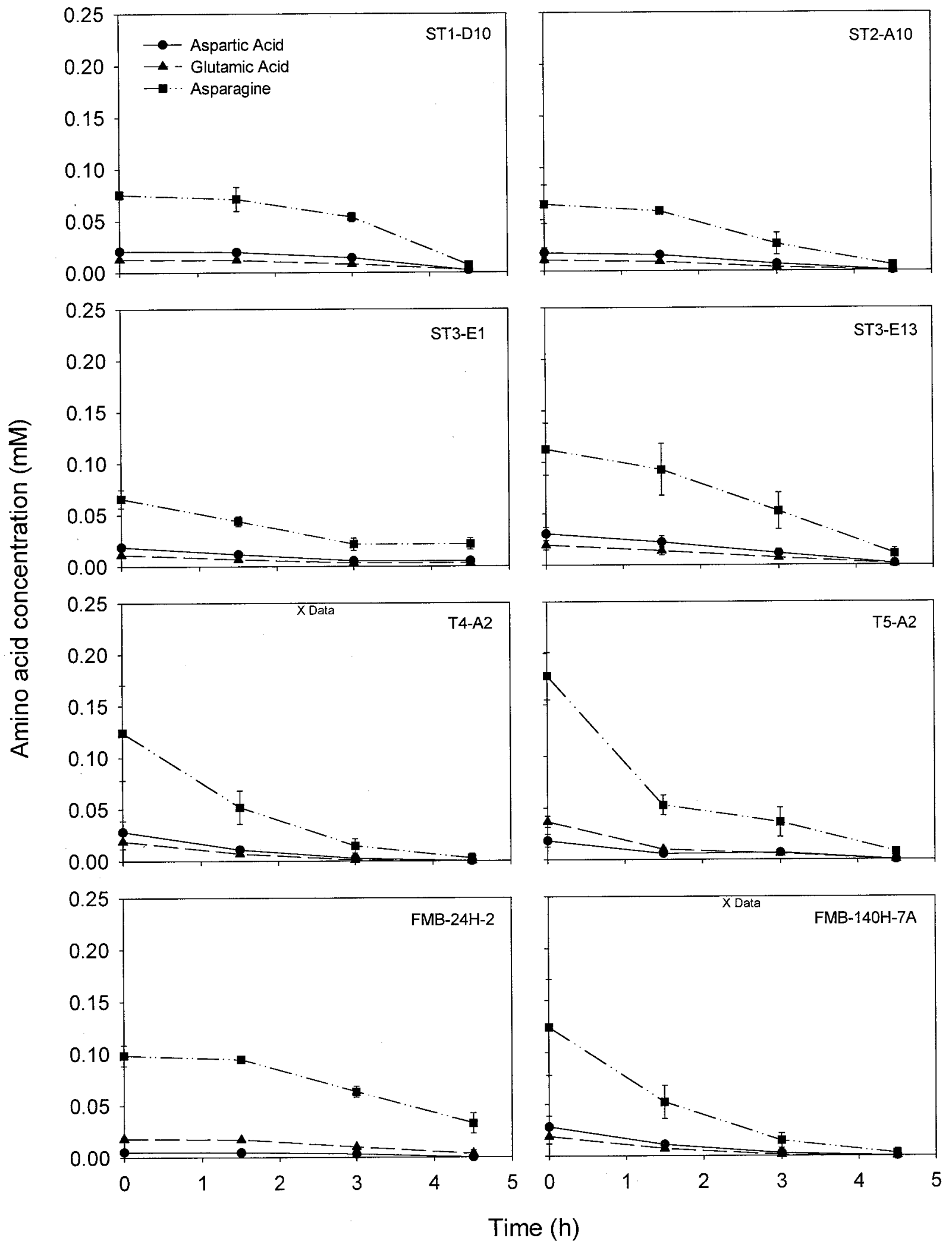

Fig. 7. Depletion of amino acids from 5\% apple juice by various strains of Metchnikowia pulcherrima at $26^{\circ} \mathrm{C}$. M. pulcherrima strains were suspended in diluted apple juice, placed in wells of plastic tissue culture plates, and incubated at $26^{\circ} \mathrm{C}$ until the indicated sampling time. Samples were filtered to remove the yeasts and the filtrate was analyzed by high pressure liquid chromatography. Bars indicate $\pm \mathrm{SD}$. 
Biolog characterization. Analysis of data from Biolog YT plates using MLCLUST program resulted in separation of the strains into five distinct clusters (Fig. 8). One cluster contained four strains, which included representatives from all three methods of isolations in three different years, and the remaining four clusters included single strains, three from the second year and one from the third year of isolation.

Genetic characterization. Phylogenetic analysis of D1/D2 sequences from the eight putative strains of $M$. pulcherrima resulted in distribution of the strains between two clades. Strain ST1-D10 clustered with the type strain of $M$. pulcherrima, whereas the other seven strains formed a closely related independent clade, which appears to represent a sister species of $M$. pulcherrima (Fig. 9). Bootstrap support for these two clades was moderate (77 and $68 \%$, respectively).

\section{DISCUSSION}

The eight strains varied in biocontrol potential of blue mold on mature Golden Delicious apple. Strains T5-A2 and T4-A2 were the most effective in reducing decay. Strain T5-A2 was also most effective in the second biocontrol test on less mature fruit at the lowest concentration of the antagonist. These two strains differ in various phenotypic characteristics important for implementation of biocontrol. Strain T5-A2 grew exceptionally well and had the strongest growth at $0^{\circ} \mathrm{C}$. This may be particularly useful for application to apples and perhaps pears, which are stored at $0^{\circ} \mathrm{C}$ or even lower temperatures.

All eight strains grew well in NYDB medium at $1^{\circ} \mathrm{C}$ and increased in population by approximately two log units in apple wounds during 1 month of storage at $1{ }^{\circ} \mathrm{C}$ followed by 5 days at $24^{\circ} \mathrm{C}$. This is a good indication of their commercial potential for biocontrol of postharvest decays of apple that are stored at $1{ }^{\circ} \mathrm{C}$ or perhaps even at lower temperatures. Lack of growth at $37^{\circ} \mathrm{C}$, the human body temperature, by all strains may reduce the number of tests necessary for registration of the antagonists by the EPA. The three strains that were killed by prolonged exposure to $37^{\circ} \mathrm{C}$ will not be suitable for any treatment that combines an antagonist with hot air (4 days at $38^{\circ} \mathrm{C}$ ), which can significantly improve decay control on apples (8).
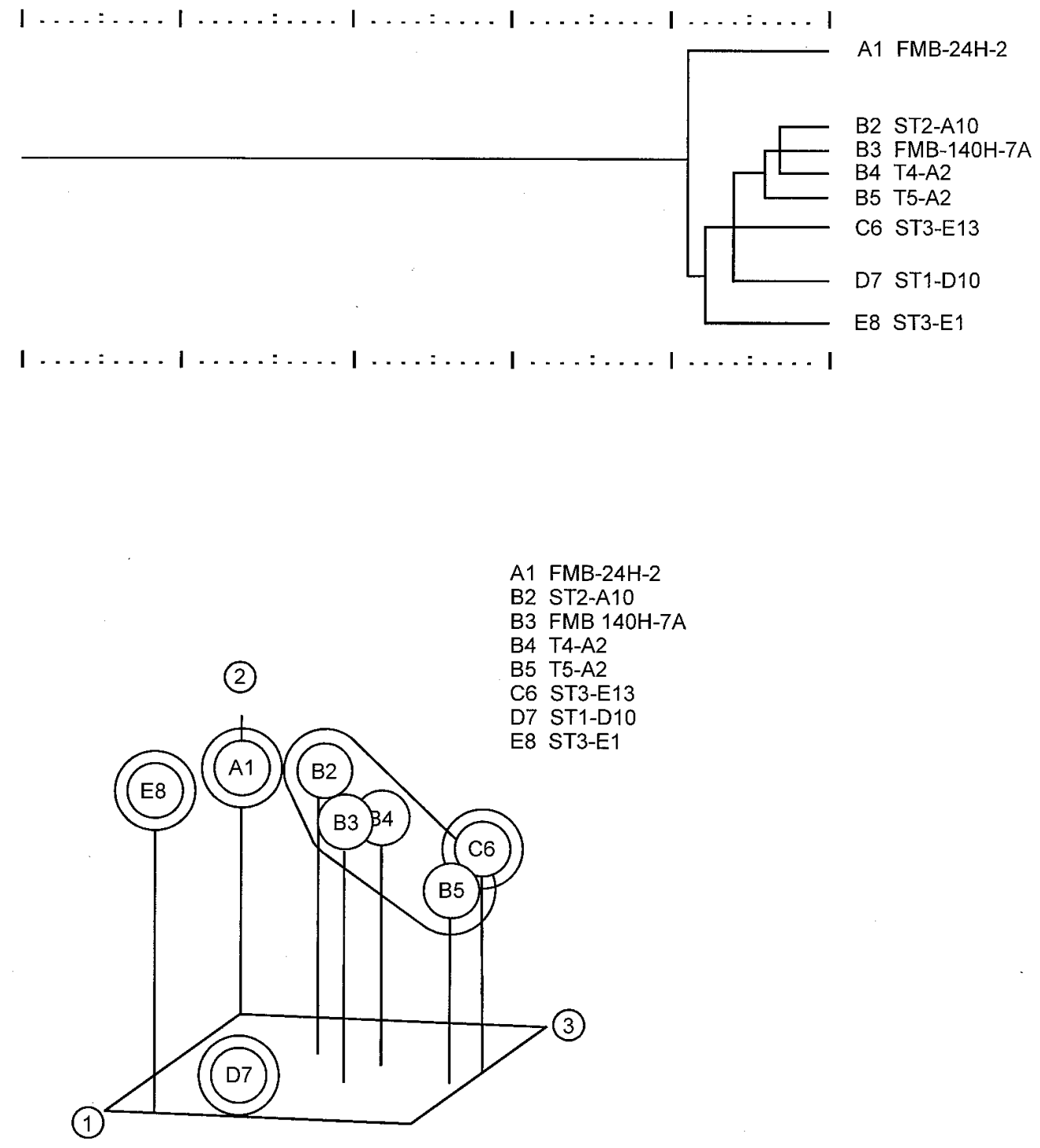

Principle Components

Fig. 8. Dendrogram and principal component analysis chart of BIOLOG profiles of the eight strains of Metchnikowia pulcherrima. YT Biolog plates were read $72 \mathrm{~h}$ after application of the yeasts. Results from the BIOLOG test were subjected to cluster analysis with the MLCLUST program. The scale in the dendrogram is in units of taxonomic distance. To help distinguish patterns in the dendrogram and principle components chart, the strains are divided into groups designated by letters. 
An increase in population by approximately two log units in apple wounds, as well as rapid removal of the amino acids from apple juice by all strains, confirmed that these antagonists are excellent colonizers of apple wounds and can thrive on apple as a substrate. However, under the conditions of the experiments, these characteristics did not differentiate strains well. A significant decline in amino acids for some strains at time 0 is intriguing and warrants further investigation. Additional tests, such as those that reflect the kinetics of growth in apple wounds, and the utilization of amino acids under different conditions may be necessary to determine potential differences among the strains.

Inert ingredients in NoScald DPA were, most likely, responsible for the rapid population decline of all eight strains because there was less decline if the yeast strains were exposed to Shield DPA at the same active ingredient concentration. Similar effects were obtained in tests with $P$. expansum conidia, where the ability of the conidia to germinate declined more rapidly after exposure to NoScald DPA than to Shield DPA (W. J. Janisiewicz, unpublished data). A few strains, including T5-A2, were very resistant to DPA and most decline in populations occurred after 5 days. This strain can be considered for biological control in packinghouses in the central and eastern United States, where it is common practice to keep DPA treatment suspensions, in which the antagonist will be applied, for up to 1 week before changing. However, pilot tests under commercial conditions will have to be conducted to deter-

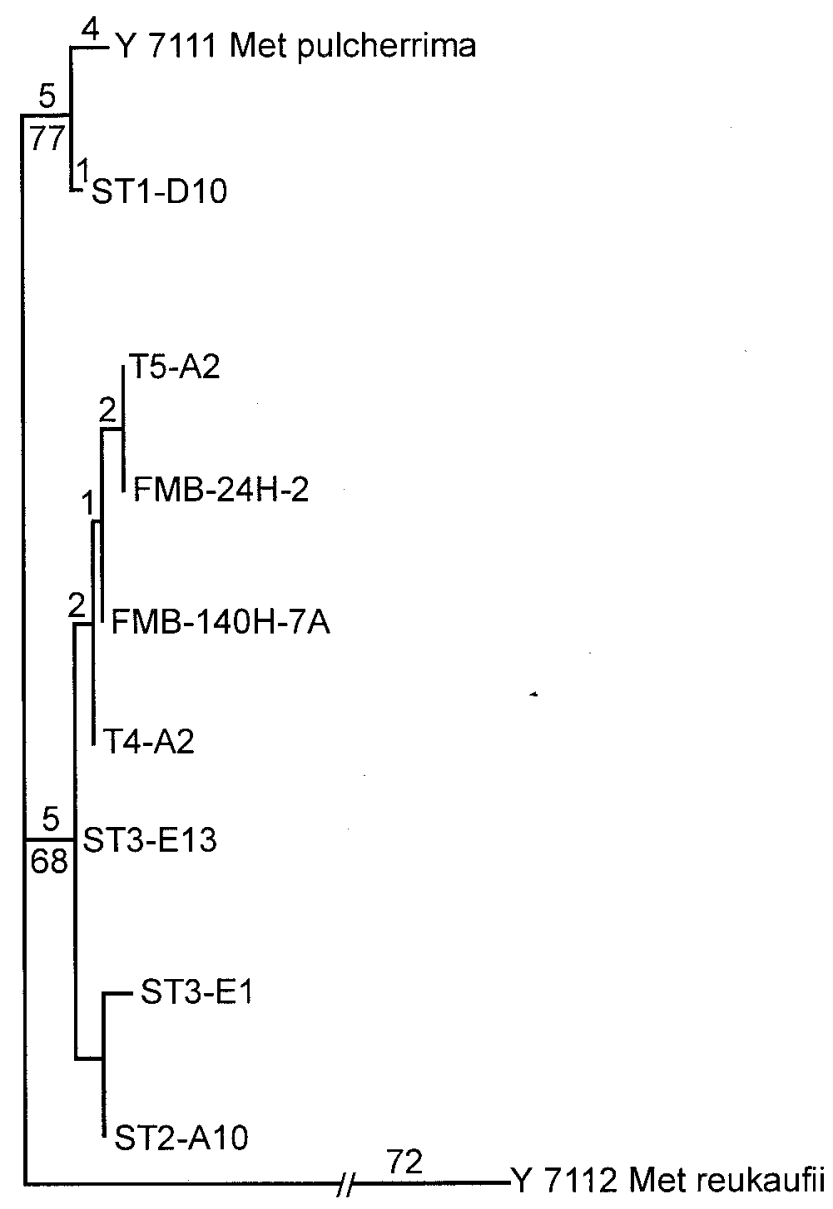

Fig. 9. Phylogenetic tree of the eight putative strains of Metchnikowia pulcherrima from a single orchard represented by one of the most parsimonious trees derived from maximum parsimony analysis. Strain NRRL Y 7111 is the type strain of $M$. pulcherrima. Numbers on the upper sides of branches indicate nucleotide differences between strains. Numbers on the lower sides of branches are bootstrap percentages based on the frequency with which a given branch appeared in 1,000 bootstrap replications. Consistency index $=$ 0.947 , retention index $=0.688$. mine if and how frequently the drenching suspension should be recharged with the antagonist.

Biotin was required for efficient growth by all strains. It will be important to determine if the availability of biotin limits growth of the yeast in fruit wounds. If this occurs, the addition of biotin may significantly increase populations of the antagonist and enhance biocontrol. Also, it may be possible to develop a mixture of the antagonists consisting of a strain of $M$. pulcherima and a yeast capable of producing biotin that may enhance $M$. pulcherima populations and improve biological control.

Analysis of the D1/D2 domain sequence data grouped strain ST1-D10 together with the type strain $M$. pulcherrima, whereas the other seven strains formed a separate clade. This indicates that ST1-D10 is the true $M$. pulcherima species strain. The most closely related strain pairs of the two clades (ST1-D10 and ST2A10) differ from one another by 12 (2\% of all nucleotides used in analysis) nucleotide substitutions (Fig. 9). From our experience, strains differing from one another by more than $1 \%$ substitutions in domain D1/D2 represent separate species (33). Consequently, it appears that the seven strains in the clade sister to $M$. pulcherima might possibly represent a new species. Additional molecular analysis is needed to further examine genetic differences among these seven strains.

Biolog data resulted in the distinct separation of strain ST1-D10, but three additional strains were also separated from the main cluster. However, strain ST1-D10 was more distant from the main cluster then the remaining three strains, particularly in 3-D (data not shown) and principal component analysis, which agrees with the analysis of the sequence data.

All M. pulcherrima strains were good antagonists against blue mold on apple. Commercial development of this antagonist will require selection of a strain with phenotypic and functional characteristics desired for the given postharvest biological control system. Strain T5-A2 appeared to be well suited for commercial development against postharvest decay on apple. $M$. pulcherrima is common in wine production $(5,18,47)$ and as a resident on many fruit $(10,19)$; thus, it may be readily accepted for application to consumable products.

Our results clearly indicate that there is a significant diversity among strains of the same yeast species (species determined by traditional method) from a single orchard. This diversity is greater in phenotypic and functional (biocontrol) characteristics than is apparent from rDNA divergence. The differences between different locations within a region or between different geographical regions may be even greater. In order to find better strains of a yeast biocontrol agent, it will be worthwhile to first explore a single location (e.g., orchard) by making multiple isolations of the same species over time. A well-characterized collection of strains of the same species will provide needed flexibility in choosing the most appropriate strain for a particular application.

Although the eight strains of $M$. pulcherrima that we tested is a relatively small sample size, we found large diversity among the strains. The diversity we observed within $M$. pulcherrima is consistent with reports from different laboratories that various strains of a species will differ in their biocontrol potential (4, $9,11,28,35,39,43)$. It also suggests that using simple genetic criteria to estimate biocontrol efficacy (45) may be difficult until desirable biocontrol properties can be equated with particular gene sequences.

\section{ACKNOWLEDGMENTS}

We thank J. Eldridge, C. Sharer, and C. Walters for their valuable technical assistance in isolations of the yeasts and conducting biocontrol and physiological characterization tests; C. J. Robnett for determining the D1/D2 sequences analyzed in this study; and L. W. Tjarks for skillful operation of the nucleic acid sequencer. 


\section{LITERATURE CITED}

1. Barnett, J. A., Payne, R. W., and Yarrow. D. 1990. Yeasts: Characteristics and Identification. Cambridge University Press, NY.

2. Basset, C. L., and Janisiewicz, W. J. 2001. Electroporation and stable maintenance of a multicopy plasmid in a Pseudomonas syringae postharvest biocontrol strain. In: Proc. 76th Cumberland-Shenandoah Fruit workers, Winchester, VA.

3. Benbow, J. M., and Sugar, D. 1999. Fruit surface colonization and biological control of postharvest diseases of pear by preharvest yeast application. Plant Dis. 83:839-844.

4. Bryk, B., Dyki, B., and Sobiczewski, P. 1998. Antagonistic effect of Erwinia herbicola on in vitro spore germination and germ tube elongation of Botrytis cinerea and Penicillium expansum. Biocontrol 43:97-106.

5. Chamberline, G., Husik, J., and Subden, R. E. 1997. Freeze-desiccation survival in wild yeast in the bloom of icewine grapes. Food Res. Int. 30:435-439.

6. Chand-Goyal, T., and Spotts, R. A. 1996. Control of postharvest pear diseases using natural saprophytic yeast colonists and their combination with low dosage of thiabendazol. Postharvest Biol. Technol. 7:51-64.

7. Chand-Goyal, T., and Spotts, R. A. 1997. Biological control of postharvest diseases of apple and pear under semi-commercial and commercial conditions using three saprophytic yeasts. Biol. Control 10:199-206.

8. Conway, W. S., Janisiewicz, W. J., Kline, J. D., and Sams, C. E. 1999. Strategy for combining heat treatment, calcium infiltration, and biological control to reduce postharvest decay of 'Gala' apples. HortScience 34:700-704.

9. Costa, E., Usall, J., Teixido, N., Garcia, N., and Vinas, I. 2000. Effect of protective agents, rehydration media and initial cell concentration on viability of Pantoea agglomerans strain CPA-2 subjected to freezedrying. J. Appl. Microbiol. 89:793-800.

10. Davenport, R. R. 1976. Distribution of yeast and yeast like organisms from aerial surfaces of developing apples and grapes. Pages 325-374 in: Microbiology of Aerial Plant Surfaces. C. H. Dickinson and T. F. Preece, eds. Academic Press, London.

11. De Curtis, Torriani, S., Rossi, F., and De Cicco, V. 1996. Selection and use of Metchnikowia pulcherrima as a biological control agent for postharvest rots of peaches and table grapes. Ann. Microbiol. Enzymol. 46:45-55.

12. Dock, L. L., Nielsen, P. V., and Floros, J. D. 1998. Biological control of Botrytis cinerea growth on apples stored under modified atmospheres. J. Food Prot. 61:1661-1665.

13. Dugan, F. M., and Roberts, R. 1994. Etiology of preharvest colonization of Bing cherry by fungi. Phytopathology 84:1031-1036.

14. El-Ghaouth, A., Smilanick, J. L., and Wilson, C. L. 2000. Enhancement of the performance of Candida saitoana by the addition of glycolchitosan for the control of postharvest decay of apple and citrus fruit. Postharvest Biol. Technol. 19:103-110.

15. Falconi, C. J., and Mendgen, K. 1994. Epiphytic fungi on apple leaves and their value for control of the postharvest pathogens Botrytis cinerea, Monilinia fructigena and Penicillium expansum. Z. Pflanzenkr. Pflanzenschutz 101(1):38-47.

16. Farris, G. A., Mannazzu, I., and Budroni, M. 1991. Identification of killer factor in the yeast genus Metschnikowia. Biotechnol. Lett. 13:297298.

17. Filonow, A. B., Vishniac, H. S., Anderson, J. A., and Janisiewicz, W. J. 1996. Biological control of Botrytis cinerea in apple by yeasts from various habitats and their putative mechanisms of antagonism. Biol. Control 7:212-220.

18. Fleet, G. H., and Heard, G. M. 1993. Yeasts: Growth during fermentation. Pages 27-54 in: Wine Microbiology and Biotechnology. G. H. Fleet, ed. Harwood Academic Publishers, Philadelphia.

19. Guerzoni, E., and Marchetti, R. 1987. Analysis of yeast flora associated with grape sour rot and of the chemical disease markers. Appl. Environ. Microbiol. 53:571-576.

20. Ippolito, A., El Ghaouth, A., Wilson, C. L., and Wisniewski, M. 2000. Control of postharvest decay of apple fruit by Aureobasidium pullulans and induction of defense responses. Postharvest Biol. Technol. 19:265272.

21. Ippolito, A., and Nigro, F. 2000. Impact of preharvest application of biological control agents on postharvest diseases of fresh fruits and vegetables. Crop Prot. 19:715-723.

22. Janisiewicz, W. J. 1987. Postharvest biological control of blue mold on apples. Phytopathology 77:481-485.

23. Janisiewicz, W. J. 1991. Control of postharvest diseases with biocontrol agents. Pages 56-68 in: The Biological Control of Plant Diseases, Proc. Int. Semin. Biol. Control Plant Dis. Virus Vectors, Tsukuba, Japan, FFTC Book Ser. 42.

24. Janisiewicz, W. J. 1996. Ecological diversity, niche overlap, and coexis- tence of antagonists used in developing mixtures for biocontrol of postharvest diseases of apples. Phytopathology 86:473-479.

25. Janisiewicz, W. J., and Bors, B. 1995. Development of a microbial community of bacterial and yeast antagonists to control wound-invading postharvest pathogens of fruits. Appl. Environ. Microbiol. 61:32613267.

26. Janisiewicz, W. J., Conway, W. S., Glenn, D. M., and Sams, C. E. 1998. Integrating biological control and calcium treatment for controlling postharvest decay of apples. HortScience 33:105-109.

27. Janisiewicz, W. J., and Jeffers, S. N. 1997. Efficacy of commercial formulation of two biofungicides for control of blue mold and gray mold of apples in cold storage. Crop Prot. 16:629-633.

28. Janisiewicz, W. J., and Marchi, A. 1992. Control of storage rots on various pear cultivars with a saprophytic strain of Pseudomonas syringae. Plant Dis. 76:555-560.

29. Janisiewicz, W. J., Peterson, D. L., and Bors, B. 1994. Control of storage decay of apples with Sporobolomyces roseus. Plant Dis. 78:466-470.

30. Janisiewicz, W. J., Tworkoski, T. J., and Sharer, C. 2000. Characterizing the mechanism of biological control of postharvest diseases on fruits with a simple method to study competition for nutrients. Phytopathology 90:1196-1200

31. Jijakli, M. H., and Lepoivre, P. 1993. Biological control of postharvest Botrytis cinerea and Penicillium expansum on apples. IOBC/WPRS Bull. Biol. Control Foliar Post-Harvest Dis. Vol. 16:106-110.

32. Jijakli, M. H, Lepoivre, P., Tossut, P., and Thonard, P. 1993. Biological control of Botrytis cinerea and Penicillium sp. on post-harvest apples by two antagonistic yeasts. Meded. Fac. Landbouwwet. Rijksuniv. Gent. $58(3 b): 1349-1358$.

33. Kurtzman, C. P., and Robnett, C. J. 1998. Identification and phylogeny of ascomycetous yeasts from analysis of nuclear large subunit (26S) ribosomal DNA partial sequence. Antonie Leeuwenhoek 73:331-371.

34. Leibinger, W., Breuker, B., Hahn, M., and Mendgen, K. 1997. Control of postharvest pathogens and colonization of the apple surface by antagonistic microorganisms in the field. Phytopathology 87:1103-1110.

35. Lima, G., De Curtis, F., Castoria, R., and De Cicco, V. 1998. Activity of the yeasts Cryptococcus laurentii and Rhodotorula glutinis against post-harvest rots on different fruits. Biocontrol Sci. Technol. 8:257-267.

36. Mari, M., Guizzardi, M., and Pratella, G. C. 1996. Biological control of gray mold in pears by antagonistic bacteria. Biol. Control 7:30-37.

37. McLaughlin, R. J., Wilson, C. L., Droby, S., Ben-Arie, R., and Chalutz, E. 1992. Biological control of postharvest diseases of grape, peach, and apple with the yeast Kloeckera apiculata and Candida guilliermondii. Plant Dis. 76:470-473.

38. McLaughlin, R. J., Wisniewski, M. E., Wilson, C. L., and Chalutz, E. 1990. Effect of inoculum concentration and salt solutions on biological control of postharvest diseases of apple with Candida sp. Phytopathology 80:456-461.

39. Migheli, Q., Gullino, M. L., Piano, S., Galliano, A., and Duverney, C. 1997. Biocontrol capability of Metchnikowia pulcherrima and Pseudomonas syringae against postharvest rots of apple under semi-commercial conditions. Meded. Fac. Landbouwwet. Rijksuniv. Gent. 62:1065-1070.

40. Piano, S., Dealessi, L., Migheli, Q., Pramotton, R., Gullino, M. L., Duverney, C., and Garibaldi, A. 1998. Biological control of postharvest diseases of apple. Pages 121-126 in: Proc. Joint Workshop Nonconventional Methods Control Postharvest Dis. Microbial Spoilage (COAST 914-915), Bologna, Italy.

41. Piano, S., Neyrotti, V., Migheli, M., and Gullino, M. L. 1997. Biocontrol capability of Metchnikowia pulcherrima against Botrytis postharvest rot of apple. Postharvest Biol. Technol. 11:131-140.

42. Rist, D. L., and Rosenberger, D. A. 1995. Storage decay of apple fruit caused by Aureobasidium pullulans. Plant Dis. 79:425.

43. Roberts, R. G. 1990. Postharvest biological control of gray mold of apple by Cryptococcus laurentii. Phytopathology 80:526-530.

44. Roberts, R. G. 1994. Integrating biological control into postharvest disease management strategies. HortScience 29:758-762.

45. Schena, L., Ippolito, A., Zahavi, T., Cohen, L., and Droby, S. 2000. Molecular approaches to assist the screening and monitoring of postharvest biocontrol yeasts. Eur. J. Plant Pathol. 106:681-691.

46. Schiewe, A., and Mendgen, K. 1992. Identification of antagonists for biological control of the post-harvest pathogens Pezicula malicorticis and Nectria galligena on apples. J. Phytopathol. 134:229-237.

47. Schutz, M., and Gafner, J. 1993. Analysis of yeast diversity during spontaneous and induced alcoholic fermentations. J. Appl. Bacteriol. 75:551558.

48. Sobiczewski, P., and Bryk, H. 1996. Biocontrol of Botrytis cinerea and Penicillium expansum on postharvest apples by antagonistic bacteria. F. Polesny, W. Muller, and R. W. Olszak, eds. Int. Conf. Integrated Fruit Prod. Cedzyna, IOBC 19:344-345.

49. Sobiczewski, P., Bryk, H., and Berczynski, S. 1996. Evaluation of epiphytic bacteria isolated from apple leaves in the control of post- 
harvest apple diseases. J. Fruit Ornam. Plant Res. 6:35-45.

50. Stack, J. P. 1998. Postharvest biological control: Commercial successes and a model for public and private sector cooperation. Invited Papers, Abstracts-1, 7th Int. Congr. Plant Pathol. Edinburgh, Scotland, BSPP, London.

51. Sugar, D., Roberts, R. G., Hilton, R. J., Righetti, T. L., and Sanchez, E. E. 1994. Integration of cultural methods with yeast treatment for control of postharvest fruit decay in pear. Plant Dis. 78:791-795.

52. Swofford, D. L. 1998. PAUP 4.0: Phylogenetic Analysis Using Parsimony. Sinauer Associates, Sunderland, MA.

53. Teixido, N., Usall, J., and Vinas, I. 1999. Efficacy of preharvest and postharvest Candida sake biocontrol treatments to prevent blue mould on apples during cold storage. Int. J. Food Microbiol. 50:203-210.

54. Teixido, N., Vinas, I., Usall, J., and Magan, N. 1998. Control of blue mold of apples by preharvest application of Candida sake grown in media with different water activity. Phytopathology 88:960-964.

55. Teixido, N., Vinas, I., Usall, J., Sanchis, V., and Magan, N. 1998. Eco- physiological responses of the biocontrol yeast Candida sake to water, temperature and $\mathrm{pH}$ stress. J. Appl. Microbiol. 84:192-200.

56. Usall, J., Teixido, N., Fons, E., and Vinas, I. 2000. Biological control of blue mold on apple by a strain of Candida sake under several controlled atmosphere conditions. Int. J. Food Microbiol. 58:83-92.

57. Vinas, I., Usall, J., Teixido, N., and Sanchis, V. 1998. Biological control of major postharvest pathogens on apple with Candida sake. Int. J. Food Microbiol. 40:9-16.

58. Wisniewski, M., Droby, S., Chalutz, E., and Eilam, Y. 1995. Effects of $\mathrm{Ca} 2+$ and $\mathrm{Mg} 2+$ on Botrytis cinerea and Penicillium expansum in vitro and on the biocontrol activity of Candida oleophila. Plant Pathol. 44:1016-1024.

59. Wisniewski, M., Wilson, C., Chalutz, E., and Hershberger, W. 1988. Biological control of postharvest diseases of fruit: Inhibition of botrytis rot on apple by an antagonistic yeast. Pages 290-291 in: 46th Annu. Meet. Electron Microsc. Soc. Am. G. E. Bailey, ed. San Francisco Press, Inc., San Francisco. 